\title{
Penerapan Riset Sistem Bata Kobel dalam Pengabdian Masyarakat di Dusun Serut, Desa Palbapang, Kecamatan Bantul, Kabupaten Bantul, Daerah Istimewa Yogyakarta
}

\author{
Susilawati Cicilia Laurentia*1, H. Ratnawati D. P. ${ }^{2}$, Agus Wibowo ${ }^{3}$ \\ ${ }^{1}$ Teknik Sipil, Universitas 17 Agustus 1945 Semarang, Indonesia \\ ${ }^{2}$ Ekonomi Manajemen, Universitas 17 Agustus 1945 Semarang, Indonesia \\ ${ }^{3}$ Hukum, Universitas 17 Agustus 1945 Semarang, Indonesia \\ *e-mail: $\underline{\text { susipi@untagsmg.ac.id }}^{1}$
}

\begin{abstract}
Abstrak
Gempa bumi Yogyakarta tahun 2006, menghancurkan Dusun Serut, namun muncul kebangkitan untuk membangun infrastruktur dengan pendekatan sinergitas kawasan. Artinya, pembangunan tidak terbatas pada penyediaan infrastruktur dasar saja, tetapi juga mengandung upaya peningkatan kualitas lingkungan dan pengembangan potensi dusun, dalam masterplan desa 2015-2030, didampingi oleh HRC Caritra. Permasalahan timbul bahwa permukiman belum tertata, khususnya Taman Perpustakaan JAYARI, tempat warga melakukan rembuk, yang dimanfaatkan juga untuk Pendidikan Anak Usia Dini (PAUD), sehingga menjadi lokasi penting dan strategis. Kebutuhan material bangunan ramah lingkungan, murah dan dapat dilakukan masyarakat sendiri, mendorong penerapan sistem bata Kobel dikembangkan di dusun ini. Langkah penerapan dilakukan dalam kerjasama dengan HRC Caritra, pendamping dusun selama ini, sebagai pembelajaran kolaboratif antara akademisi-mitra-masyarakat dan melibatkan mahasiswa KKN Tematik kurikulum MBKM. Pertama, dilakukan survei untuk menghasilkan rancangan desain. Selanjutnya dilakukan sosialisasi dan pelatihan sistem bata Kobel. Akhirnya, pelaksanaan dikerjakan dalam pengabdian masyarakat sebagai momen pembelajaran kolaboratif dari berbagai pihak: dosen-mahasiswa; masyarakat dan HRC Caritra, bersinergi melaksanakan pembangunan penataan taman. Hasil kegiatan akhirnya diserah terimakan bersama asset alat pres Bata Kobel. Dapat disimpulkan bahwa penerapan sistem bata Kobel memberikan kesempatan bagi dosen, mahasiswa, mitra dan masyarakat bersinergi menciptakan suatu taman ramah lingkungan, murah dan terjangkau serta menyatukan unsur akademisi-swasta-masyarakat dalam pengembangan kesejahteraan dusun.
\end{abstract}

Kata kunci: Bata Kobel, Kurikulum MBKM-KKN Tematik, Pembelajaran Kolaboratif, Ramah Lingkungan, Sinergitas Akademisi-Swasta-Masyarakat

\begin{abstract}
The 2006 Yogyakarta earthquake destroyed Serut Hamlet, but trigger to build infrastructure in regional synergy approach. The development is not limited providing basic infrastructure, but also improve environmental quality and develop the hamlet's potential, in the masterplan 2030, accompanied by HRC Caritra. Problems that arise include: unorganized settlements such as the JAYARI Library Park, where the community gathers. This park is also used for Early-Childhood Education (PAUD) activities, as an importantstrategic location. The need for environmentally-friendly construction materials, low-cost and self-produced by the community, encourage the implementation of the Kobel brick system to be developed in this location. The steps were carried out in collaboration with HRC Caritra, the assistant so far, as collaborative learning between academics-partners-community and involving students of the Thematic-KKN, MBKM curriculum. First, a survey was conducted to produce design-draft. Furthermore, socialization and training of the Kobel brick system. Finally, the implementation is carried out together in community service, which makes collaborative learning moments from various stakeholders. The results of the activity were finally handed over together with the assets of the Kobel Bata press tool. It can be concluded that the implementation of the Kobel brick system provides an opportunity for lecturers, students, partners and the community to work together creating an environmentally-friendly, cheap and affordable park and unite academic-private-community elements in the development of village welfare.
\end{abstract}

Keywords: Academic-Private-Community Synergy, Collaborative Learning, Environmentally-Friendly, Kobel Bricks, Thematic-KKN MBKM-Curriculum 


\section{PENDAHULUAN}

\subsection{Latar Belakang dan Permasalahan}

Dusun Serut terletak di Desa Palbapang yang berada di Kecamatan Bantul, Kabupaten Bantul, Daerah Istimewa Yogyakarta. Dusun Serut berjarak sekitar $17 \mathrm{~km}$ dari pusat ibukota Daerah Istimewa Yogyakarta (DIY) dan sekitar $5 \mathrm{~km}$ ke selatan dari pusat ibukota Kabupaten Bantul. Cukup jauh dari pusat perkotaan dan pusat layanan perkotaan, tidak membuat Dusun Serut berhenti bersama jarak. Mereka terus berbenah dan berkembang seiring dengan perjalanan waktu. Sebagai sebuah dusun kecil dengan luas wilayah sekitar 57,25 Ha, Dusun Serut termasuk maju dibandingkan dengan dusun-dusun kebanyakan di Kabupaten Bantul maupun DIY.

Pasca gempa bumi Yogyakarta tahun 2006, kegiatan pembangunan di Dusun Serut menggunakan pendekatan sinergitas kawasan. Hasil bentuk kegiatan pembangunan tidak terbatas pada penyediaan infrastruktur dasar saja, tetapi juga mengandung upaya peningkatan kualitas lingkungan dan pengembangan potensi dusun. Pembangunan di Dusun Serut telah direncanakan hingga tahun 2030 dalam masterplan perencanaan dusun yang didampingi oleh HRC Caritra.

Permasalahan yang masih ada di Dusun Serut hingga saat ini adalah permukiman yang belum tertata antara lain adalah Taman Perpustakaan JAYARI, yang merupakan sarana untuk keperluan peningkatan kualitas sumber daya manusia dengan membaca buku dan melaksanakan berbagai kegiatan pembelajaran. Selain untuk perpustakaan, taman ini juga dimanfaatkan untuk kegiatan Pendidikan Anak Usia Dini (PAUD) dan tempat warga dusun ketika perlu melakukan rembuk untuk pengembangan Dusun Serut. Hal ini membuat Taman Perpustakaan JAYARI menjadi lokasi penting dan strategis bagi Dusun Serut.

Pembangunan infrastruktur juga menyebabkan banyaknya sisa material yang tidak termanfaatkan. Saat ini sedang berlangsung pembangunan IPAL yang meninggalkan bahan galian berupa tanah yang dapat dimanfaatkan untuk mengembangkan inovasi soil press interlocking brick atau BATA Kobel yang dikembangkan Universitas 17 Agustus 1945 (UNTAG) Semarang. Kobel sendiri merupakan akronim dari "kokok beluk" yaitu sebutan untuk burung hantu yang merupakan lambang dari UNTAG Semarang. BATA Kobel adalah bata ramah lingkungan yang dibuat dengan bahan dasar tanah dicampur sedikit semen dan air yang kemudian dipres. Kelebihan bata Kobel selain ramah lingkungan juga murah, karena bahan dasarnya dari tanah atau sisa bahan bangunan yang dapat ditemukan di lingkungan sekitar kita.

Permasalahan dan potensi tersedianya bahan tersebut, mendorong penerapan riset inovasi BATA Kobel untuk peningkatan kualitas lingkungan di Perpustakaan JAYARI. Peningkatan kualitas Taman Perpustakaan JAYARI menjadi bagian dari rencana pembangunan dusun hingga 2030, selain itu harapannya penerapan BATA Kobel di Taman Perpustakaan JAYARI dapat menjadi pilot project agar nantinya inovasi soil press interlocking brick atau BATA Kobel dapat diterapkan untuk penataan permukiman di Dusun Serut selanjutnya dalam kegiatan Badan Usaha Milik Dusun (BUMDus). Oleh karena itu, Dusun Serut dapat menjadi lokasi penerapan riset dalam pengabdian masyarakat dan sekaligus menjadi lokasi KKN Tematik bagi mahasiswa Universitas 17 Agustus 1945 (UNTAG) Semarang. Hal ini menjadi kesempatan pembelajaran kolaboratif yang berorientasi pada penelitian dan pengabdian masyarakat untuk mendukung ketercapaian Indikator Kinerja Utama (IKU) Direktorat Jenderal Pendidikan Tinggi Riset dan Teknologi, yaitu menyiapkan mahasiswa dalam dunia kerja dan usaha secara konkret.

Beberapa permasalahan nyata yang dihadapi mitra, yaitu masyarakat Dusun Serut dan HRC Caritra yang mendampingi masyarakat Dusun Serut antara lain:

1. Lingkungan Perpustakaan JAYARI yang belum tertata sehingga kurang nyaman untuk pembelajaran masyarakat.

2. PAUD EDELWYS yang akan menghadapi akreditasi pada tahun 2022.

3. Kekuatan finansial maupun pengetahuan teknologi tepat guna yang masih kurang dalam menata dan meningkatkan infrastruktur dusun menjadi wilayah pembelajar bagi semua orang yang datang di Dusun Serut Hijau.

Lokasi Perpustakaan JAYARI dengan lingkungan sekitarnya ditunjukkan pada Gambar 1. 


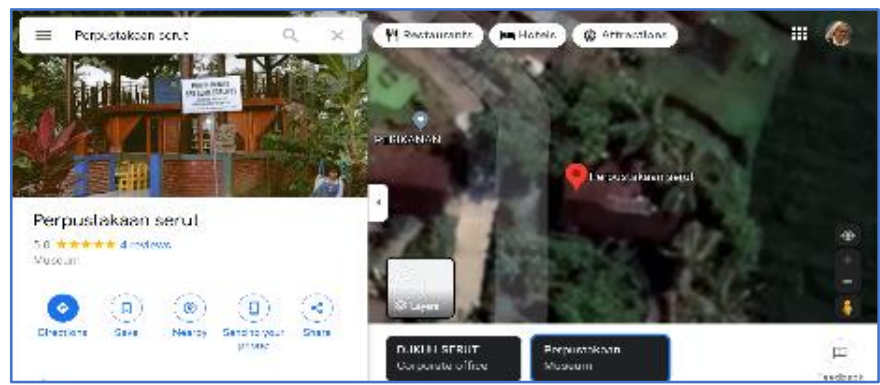

Gambar 1. Lokasi Perpustakaan JAYARI - PAUD EDELWYS (Google Map)

Untuk mencapai Perpustakaan JAYARI Dukuh Serut dengan jarak $143 \mathrm{Km}$, ditempuh dengan perjalanan berkendaraan via jalan tol Semarang-Solo, dalam waktu 2 jam 45 menit seperti ditunjukkan dalam Gambar 2.

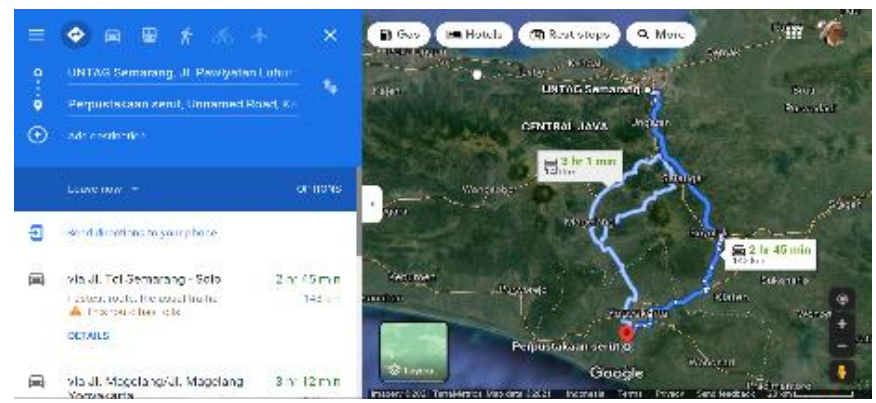

Gambar 2. Route perjalanan dari UNTAG Semarang ke Perpustakaan Serut (Google Map)

Sedangkan lokasi pengabdian secara detail dibuat waktu survei lokasi awal kegiatan melalui foto udara dengan perangkat Drone, ditunjukkan seperti dalam Gambar 3, dan sketsa yang dihasilkan ditunjukkan seperti dalam Gambar 4.

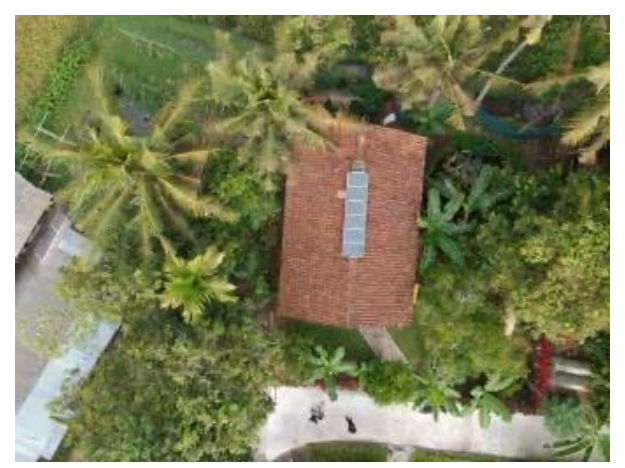

Gambar 3. Kondisi lokasi Taman Perpustakaan Jayari Dusun Serut Desa Palbapang, Kecamatan Bantul, Kabupaten Bantul (dokumentasi foto drone)

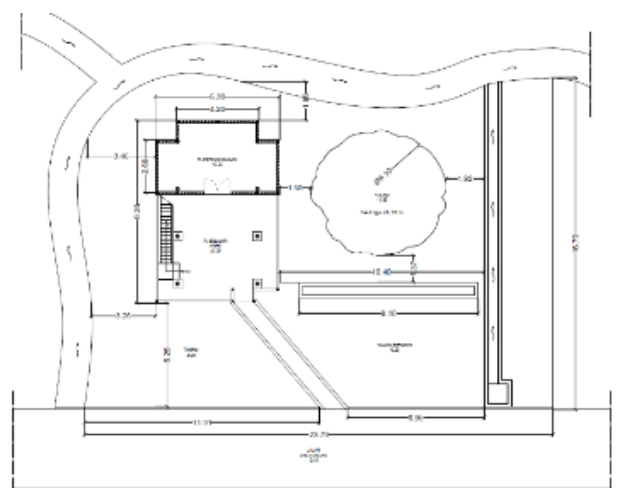

Gambar 4. Gambar layout Perpustakaan Jayari Dusun Serut dan sekitarnya 


\subsection{Tujuan dan Sasaran Kegiatan}

Tujuan dan sasaran Pengabdian masyarakat ini adalah:

1. Mendapatkan solusi permasalahan mitra dalam menata dan meningkatkan kualitas Perpustakaan JAYARI sehingga semakin menunjang kegiatan pembelajaran masyarakat.

2. Mendapatkan solusi permasalahan mitra terhadap penataan lingkungan PAUD EDELWYS Dusun Serut untuk persiapan akreditasi tahun 2022.

3. Memberikan solusi permasalahan mitra dalam meningkatkan infrastruktur dusun sesuai dengan masterplan dusun yang telah dibuat sampai dengan tahun 2030 melalui unit usaha dusun dalam bentuk Badan Usaha Dusun (BUMDus) yang menyediakan material konstruksi bata Kobel.

4. Kesempatan pembelajaran kolaboratif bagi mahasiswa bersama mitra masyarakat Dusun Serut dalam mendukung tercapainya IKU.

\subsection{Kajian Literatur}

Kajian literatur yang mendukung kegiatan pengabdian masyarakat ini terkait dengan sistem bata Kobel sebagai material ramah lingkungan, kurikulum MBKM - KKN Tematik, pembelajaran kolaboratif, sinergitas akademisi-swasta-masyarakat.

\subsubsection{Sistem Bata Kobel sebagai Material Ramah Lingkungan}

Isu lingkungan adalah mendesak dengan tuntutan untuk lebih inovatif dalam menciptakan sesuatu yang ramah lingkungan, bermanfaat, dan memberikan nilai tambah (Vania Zulfa, 2016). Salah satu penemuan dalam bidang konstruksi, yaitu material bahan bangunan, seperti yang dilakukan tim dari Universitas 17 Agustus 1945 (UNTAG) Semarang, berhasil menciptakan alat cetak bata Kobel yang mudah digunakan masyarakat (Susilawati e. , 2016). Inisiasi inovasi bata Kobel ini diterapkan di Dusun Serut Desa Palbapang, dalam suatu proyek penataan Taman Perpustakaan JAYARI dan PAUD Edelwys. Bahan dasar yang digunakan untuk bata Kobel ini adalah tanah, sehingga akan menghasilkan material bahan bangunan/bata yang ramah lingkungan (Susilawati C.L., 2019). Kelebihan bata Kobel selain ramah lingkungan juga murah (Susilawati C.L., 2019), karena dalam penyusunan konstruksi lebih lanjut tidak/hanya sedikit memerlukan material tambahan yang mahal, seperti besi ataupun semen (Susilawati C.L., 2019).

\subsubsection{Kurikulum MBKM - KKN Tematik}

Kuliah Kerja Nyata Tematik (KKN Tematik) merupakan Bentuk Kegiatan Pembelajaran (BKP) yang mengasah softskill kemitraan antara perguruan tinggi dan desa serta kolaborasi lintas disiplin dan leadership mahasiswa di dalam pengelolaan program pembangunan di wilayah pedesaan (Prof. DR. H. Suparno, MSi, 2021). BKP Membangun Desa / KKN Tematik memberikan pengalaman belajar kepada mahasiswa untuk hidup di tengah masyarakat di luar kampus, dengan secara langsung berkolaborasi bersama masyarakat mengidentifikasi potensi dan menangani masalah, serta mengembangkan potensi suatu desa / daerah dan meramu solusi untuk masalah yang ada di desa /daerah tersebut. BKP Membangung Desa / KKNT ini dilaksanakan selama 6 12 bulan untuk diakui maksimal 20-40 SKS. KKNT merupakan kegiatan pengabdian kepada masyarakat yang dilaksanakan oleh mahasiswa multidisplin dengan tema khusus yang bersifat insidental sesuai dengan kebutuhan masyarakat atau atas permintaan pihak eksternal (LP3M Universitas Udayana, 2020).

KKN Tematik mempunyai tujuan untuk memberikan kesempatan kepada mahasiswa dalam memanfaatkan ilmu pengetahuan, teknologi, dan keterampilan yang dimilikinya, bekerjasama dengan banyak pemangku kepentingan di lapangan melalui keterlibatan mahasiswa serta membantu percepatan pembangunan di wilayah pedesaan bersama dengan Kementerian Desa PDTT. KKN Tematik juga tidak lepas dari tujuan pelaksanaan KKN secara umum, yaitu: 1) Meningkatkan empati dan kepedulian mahasiswa; 2) Menerapkan IPTEKS secara team work dan interdispliner; 3) Menanamkan nilai kepribadian: keuletan, etos kerja dan tangung jawab; kemandirian, kepemimpinan dan kewirausahaan (DRPM - ITS, 2021). 
Fokus program KKN Tematik berupa tujuan-tujuan pembangunan berkelanjutan (Sustainable Development Goals/SDGs), meliputi 17 tujuan (goals) seperti diilustrasikan dalam Gambar 5. Semua aktivitas SDGs diarahkan memperkuat implementasi dan menghidupkan kembali kemitraan global untuk pembangunan yang berkelanjutan, kecuali SDGs ke 11 (DRPM ITS, 2021).

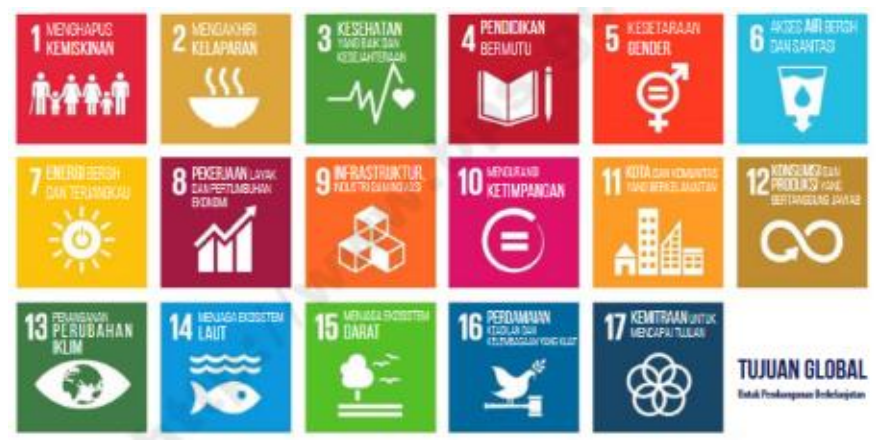

Gambar 5. Tujuan pembangunan berkelanjutan (SDGs)

\subsubsection{Pembelajaran Kolaboratif}

Pembelajaran kolaboratif yang melibatkan domain kognitif, afektif dan psikomotorik sangat efektif dan dapat mendorong peserta didik berpikir analitis, serta terampil memecahkan masalah dan isu dunia nyata (Apriono, 2013). Hal ini dapat dilaksanakan dalam suatu kegiatan pengabdian masyarakat yang melibatkan mahasiswa, dosen, masyarakat maupun mitra lembaga di luar akademisi. Berbagai pihak terkait mengalami pembelajaran yang senantiasa berkelanjutan dalam aspek pengetahuan, relasi kerjasama untuk mewujudkan suatu hasil kerja yang semakin lebih baik (Caritra, 2021). Proses pembelajaran kolaboratif ini mendorong transformasi bagi mahasiswa dalam mempersiapkan diri dan berlatih sehingga siap untuk masuk dalam dunia kerja setelah lulus (IKU 1), dari pengalamannya di luar kampus yaitu di tengah masyarakat (IKU 2) (Prof. DR. Drs. Suparno, 2021). Bagi dosen ataupun pengajar yang telah melakukan riset dan dapat diterapkan ataupun digunakan masyarakat sehingga sungguh bermanfaat (IKU 3 dan 5). Kegiatan pengabdian masyarakat yang didasarkan pada model pembelajaran kolaboratif dengan melibatkan pula mitra lembaga non akademisi, yaitu lembaga pendamping masyarakat juga menciptakan suatu kelas yang kolaboratif dan partisipatif (IKU 7) (Dirjen Dikti Kemendikbud, 2021).

Pembelajaran kolaboratif akan diikuti dengan metode pembelajaran yang inovatif pula, sehingga membentuk dosen yang berkualitas. Hal ini akan meningkatkan daya kompetisi dalam indicator kinerja utama yang telah dicanangkan dalam program kampus merdeka. Indikator kinerja utama (IKU) tersebut dijelaskan seperti dalam Gambar 6 berikut ini.

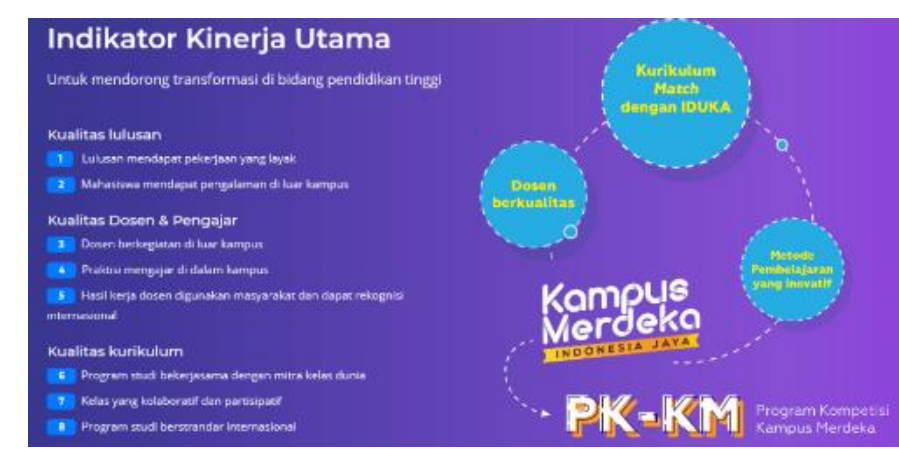

Gambar 6. Indikator kinerja utama program kompetisi kampus merdeka

\subsubsection{Sinergitas Akademisi-Swasta-Masyarakat}

Membangun sinergi untuk menumbuhkan ketangguhan masyarakat dalam pembangunan desa dan penerapan inovasi pengembangan desa, dibutuhkan kerjasama antara pemerintah dan 
akademisi maupun lembaga yang bergerak dibidang pendampingan masyarakat. Peningkatan pemberdayaan masyarakat menjadi komitmen akademisi untuk meningkatkan potensi sumber daya yang ada di pedesaan agar dapat dimanfaatkan secara proporsional. Hal ini diwujudkan dalam kegiatan nyata, yaitu menciptakan taman perpustakaan yang menarik agar budaya literasi dari masyarakat meningkat sehingga pengetahuan dapat berkembang dan diharapkan akan meningkatkan kesejahteraan bagi masyarakat yang ada di sekeliling desa (Susilawati, Ratnawati, \& Agus, Laporan Pengabdian Masyarakat Penerapan Riset Sistem Bata KOBEL di Dusun Serut Palbapang Bantul Yogyarkarta, 2021). Upaya untuk pengembangan desa di kalangan masyarakat tidak hanya dapat dilakukan atau dibebankan pada salah satu unsur saja yaitu masyarakat desa, namun memerlukan sinergitas dari multi pihak, sehingga pendekatan model triple helix yang melibatkan kerjasama diantara tiga unsur perguruan tinggi, pengusaha, pemerintah dapat dipergunakan untuk menanggulangi masalah kompleksitas tersebut sehingga dapat menghasilkan sistem dan pengembangan desa yang komprehensif. Interaksi antara tiga institusi penting merupakan kunci utama bagi peningkatan kondisi yang kondusif bagi inovasi. Irawati (2007) mengemukakan model ini melibatkan universitas sebagai centre of excellence melalui aktivitas akademik berbasis penelitian dan pengembangan, industri sebagai penyedia permintaan pelanggan berbasis aktivitas komersial serta penelitian dan pengembangan, dan pemerintah sebagai pembuat kebijakan dimana intergrasi dari ketiga aktor yang berbeda ini secara ideal akan meningkatkan keberlimpahan pengetahuan dalam suatu wilayah dan pada gilirannya meningkatkan pengembangan daya saing ekonomi baik di tingkat lokal maupun nasional.

\section{METODE}

Metode pelaksanaan kegiatan pengabdian masyarakat dalam uji coba penerapan teknologi tepat guna sistem Bata Kobel untuk peningkatan kualitas Perpustakaan JAYARI dan PAUD EDELWYS dan sekitarnya ini sekaligus menjadi pembelajaran kolaboratif mahasiswa UNTAG Semarang dan masyarakat yang melibatkan pula dosen UNTAG Semarang dan mitra Kerjasama dengan HRC Caritra. Metode pelaksanaan ini diilustrasikan seperti dalam Gambar 5.

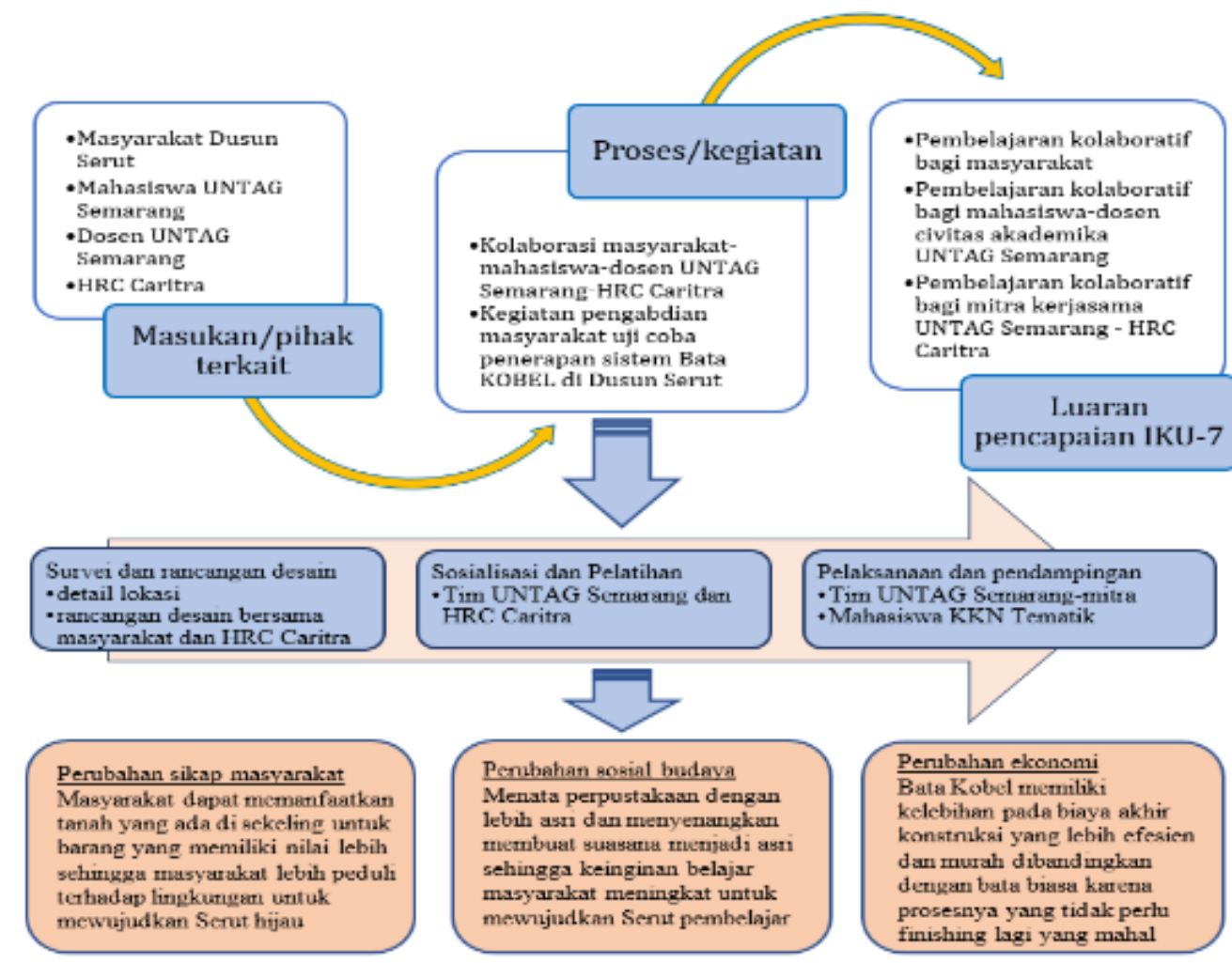

Gambar 5. Metode pelaksanaan kegiatan pengabdian masyarakat dan sisi harapan perubahan setelah kegiatan 


\section{HASIL DAN PEMBAHASAN}

Hasil kegiatan pengabdian masyarakat ini meliputi tahapan antara lain: 1) Survei dan rancangan desain: detail lokasi dan rancangan desain bersama masyarakat dan HRC Caritra, 2) Sosialisasi dan Pelatihan: Tim UNTAG Semarang dan HRC Caritra dan 3) Pelaksanaan dan pendampingan: Tim UNTAG Semarang-mitra dengan Mahasiswa KKN Tematik. Akhir kegiatan ini ditutup dalam suatu serah terima asset kepada masyarakat berupa hasil pelaksanaan konstruksi yang perlu disempurnakan oleh masyarakat dan 2 alat pres bata Kobel yang menjadi modal masyarakat dalam mengembangkan infrastruktur dusun secara berkelanjutan.

\subsection{Rancangan Desain Taman Perpustakaan JAYARI}

Kondisi Perpustakaan JAYARI dan PAUD EDELWYS yang ada saat ini diilustrasikan seperti dalam Gambar 7, 8, 9 berikut ini:

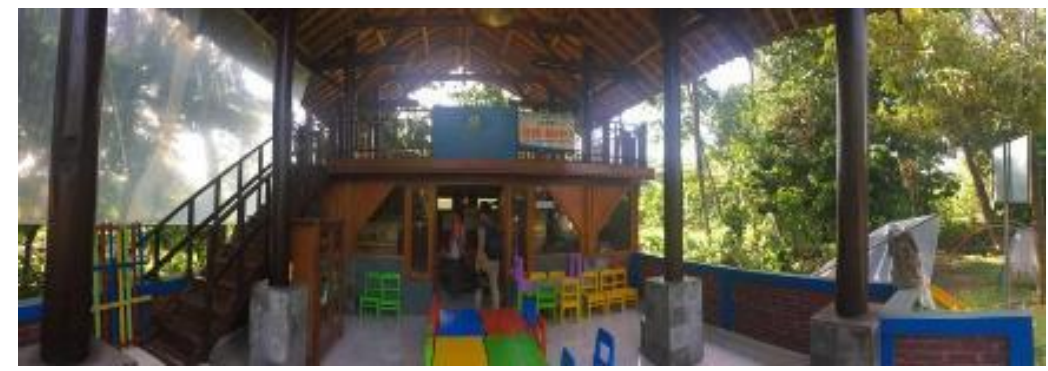

Gambar 7. Bangunan perpustakaan JAYARI
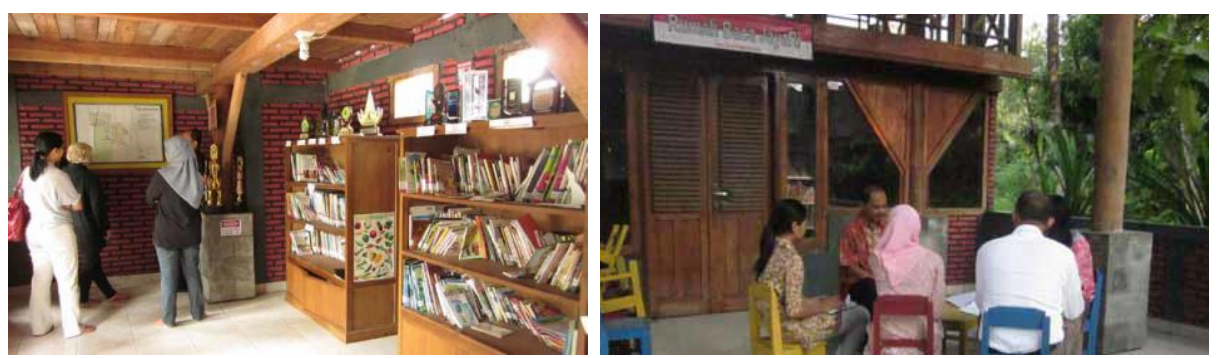

Gambar 8. Ruang baca kegiatan pertemuan warga di Perpustakaan JAYARI

Sejalan dengan visi Serut Hijau 2030, pembangunan perpustakaan JAYARI juga menekankan konsep keberlanjutan. Material bangunan yang digunakan untuk perpustakaan ini adalah material bekas layak bangun ulang atau recycled construction materials. Secara fungsi, Perpustakaan ini juga dimanfaatkan untuk kegiatan PAUD, ruang kumpul warga, dan juga terdapat taman bermain yang dilengkapi dengan kolam ikan untuk sarana rekreasi warga Dusun Serut (Gambar 9).
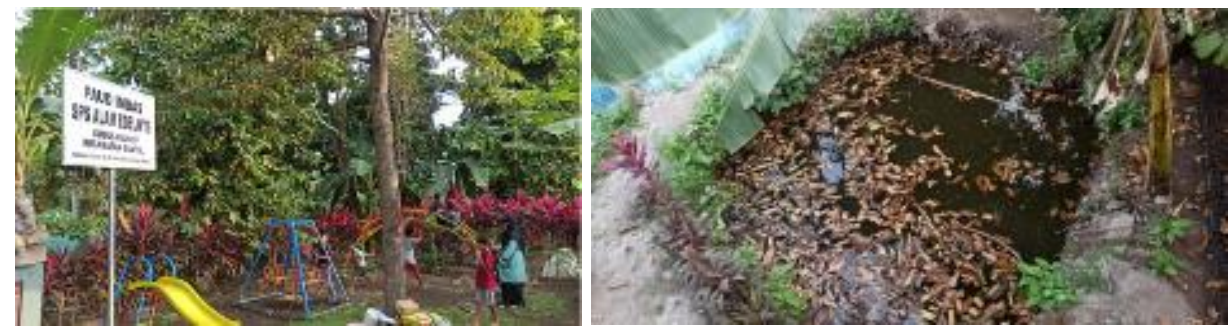

Gambar 9. Taman bermain dan kolam taman Perpustakaan JAYARI

Rancangan desain yang dikembangkan juga menggunakan bahan material ramah lingkungan yaitu sistem bata Kobel yang memiliki bahan dasar tanah setempat. Siteplan rencana revitalisasi taman PAUD di Dusun Serut diilustrasikan seperti dalam Gambar 10, dan rencana pembuatan taman, kolam serta tempat duduk taman ditunjukkan dalam Gambar 11. 


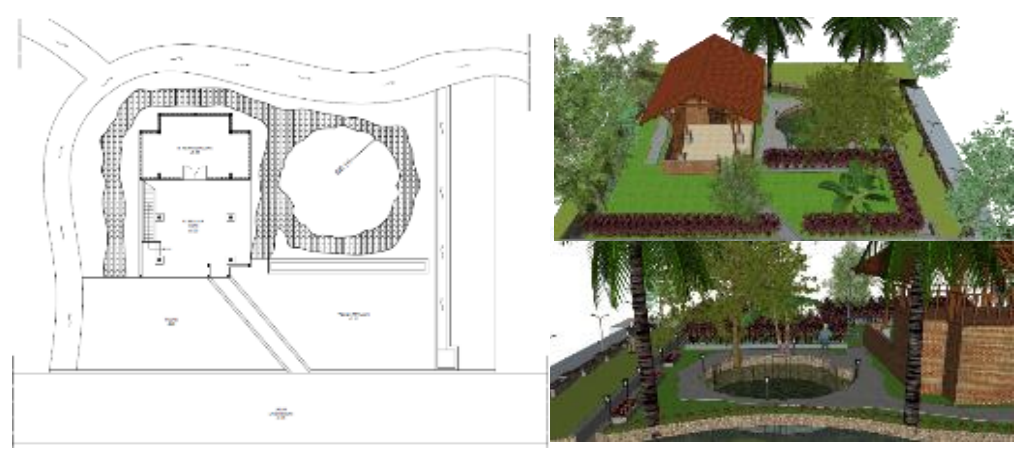

Gambar 10. Siteplan rencana revitalisasi taman PAUD di Dusun Serut

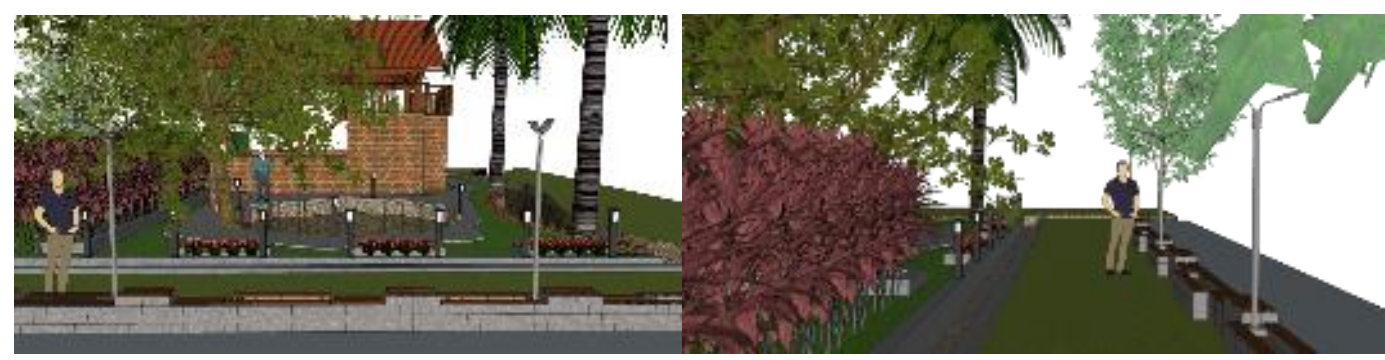

Gambar 11. Rencana pembuatan tempat duduk taman

\subsection{Kegiatan Sosialisasi dan Pelatihan}

Konsep pemberdayaan masyarakat di sekitar lingkungan tempat tinggal merupakan bentuk pelaksanaan dari pembangunan yang berpusat pada manusia. Pelaksanaan kegiatan sosialisasi dan pelatihan sistem bata Kobel diberikan bagi kader masyarakat Dusun Serut, Desa Palbapang, Kecamatan Bantul, Kabupaten Bantul, Daerah Istimewa Yogyakarta, yang diadakan oleh tim dosen, mahasiswa Universitas 17 Agustus 1945 Semarang dan mitra HRC Caritra. Kegiatan ini dilakukan dalam sosialisasi secara teori, yang dilanjutkan dalam praktek pelatihan dan pendampingan antara masyarakat, mahasiswa dan kepala Dusun Serut. Peserta pelatihan yang diikuti oleh 25 peserta masyarakat pria dari Dusun Serut yang berprofesi sebagai kepala keluarga, pensiunan dan buruh lepas dibantu oleh mahasiswa Fakultas Teknik Universitas 17 Agustus 1945 Semarang. Langkah pembuatan bata Kobel: tanah disaring terlebih dahulu agar mendapatkan butiran yang tidak terlalu besar, kemudian ditambahkan sedikit semen sebagai bahan perekat, dicampurkan dalam kondisi kering sampai merata. Selanjutnya campuran ini dilembabkan dengan menambahkan air yang disiramkan secara lembut sampai dalam kondisi kelembaban yang cukup (Gambar 12).
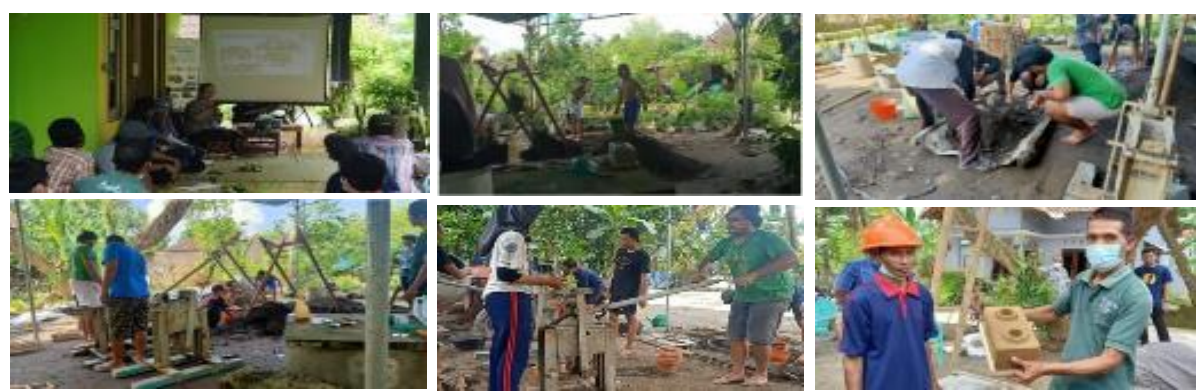

Gambar 12. Dokumentasi kegiatan sosialisasi dan pelatihan

\subsection{Kegiatan Pelaksanaan Konstruksi}

Pelaksanaan konstruksi juga melibatkan mahasiswa KKN tematik dan masyarakat dengan didampingi oleh tim dan lembaga mitra. Kegiatan pelaksanaan konstruksi meliputi kegiatan pencetakan atau produksi bata Kobel, pembersihan lokasi sekitar taman perpustakaan, pelaksanaan konstruksi kolam yaitu pemancangan bambu pada tepi kolam, pemasangan lantai 
taman. Pemberangkatan mahasiswa dari kampus dan penyambutan kepala dusun di Dusun Serut ditunjukkan dalam dokumentasi foto pada Gambar 13-22.
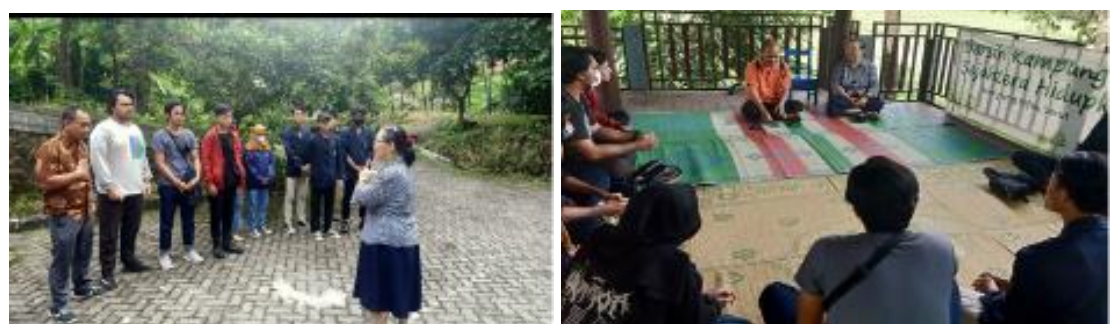

Gambar 13. Berdoa sebelum pemberangkatan dan penyambutan kepala dusun

Dinamika kegiatan di dusun selanjutnya diilustrasikan seperti dalam gambar-gambar berikut.
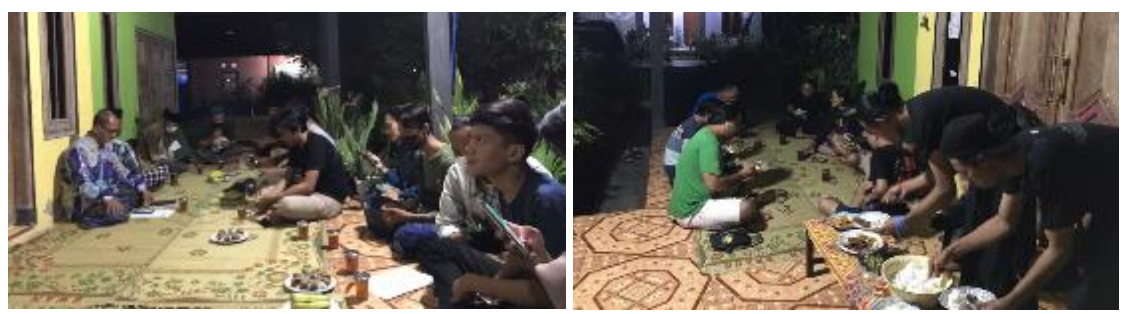

Gambar 14. Perjumpaan dengan warga masyarakat, makan malam bersama
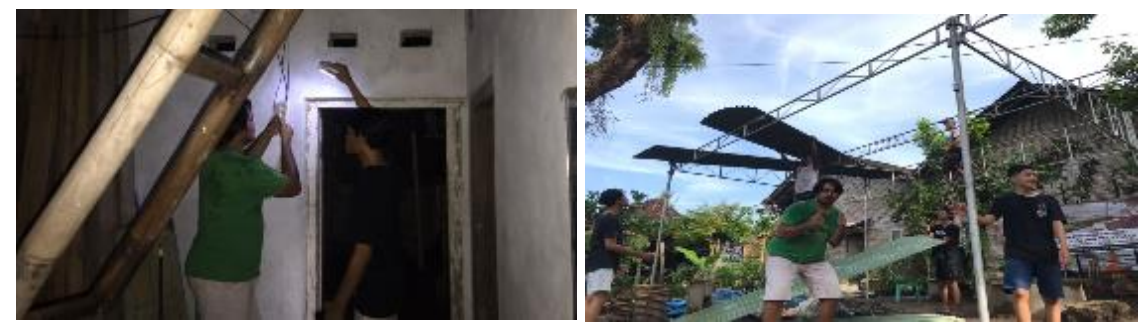

Gambar 15. Belajar menjadi tukang listrik dan siapkan tempat kerja
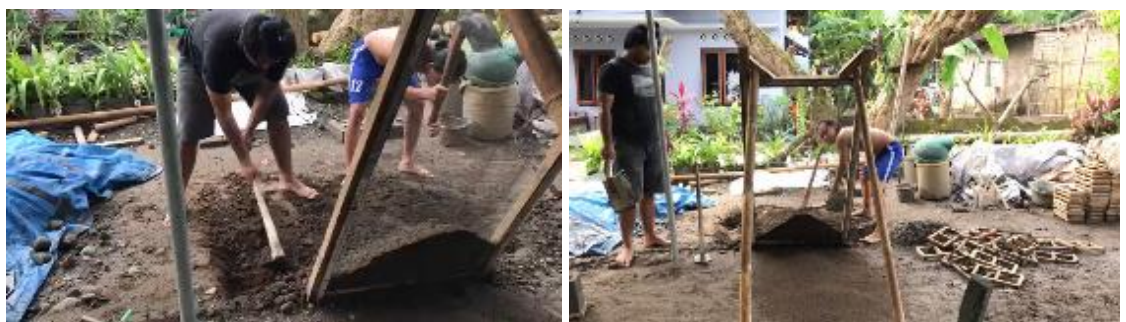

Gambar 16. Gali tanah setempat dan ayak

Selanjutnya campur kering kemudian dilembabkan dengan tambahkan air isikan ke dalam alat pres, tekan dan angkat hasilnya. Nah, boleh bangga akan hasil, tapi masih perlu perawatan.

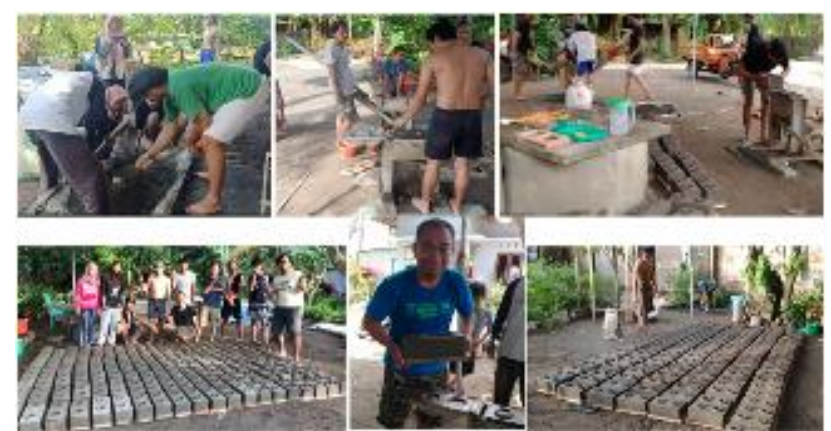

Gambar 17. Proses pelaksanaan produksi bata Kobel 

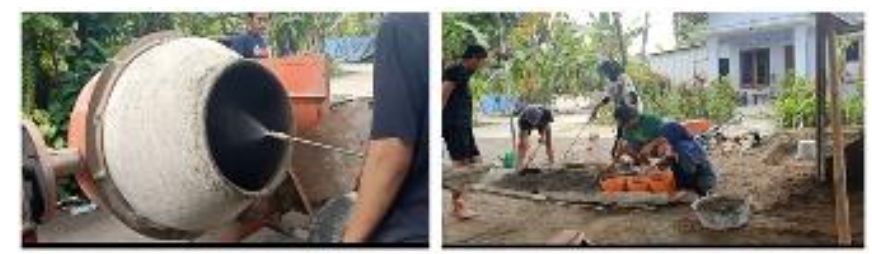

Gambar 18. Perkembangan lebih lanjut dengan dibantu alat molen dan sprayer
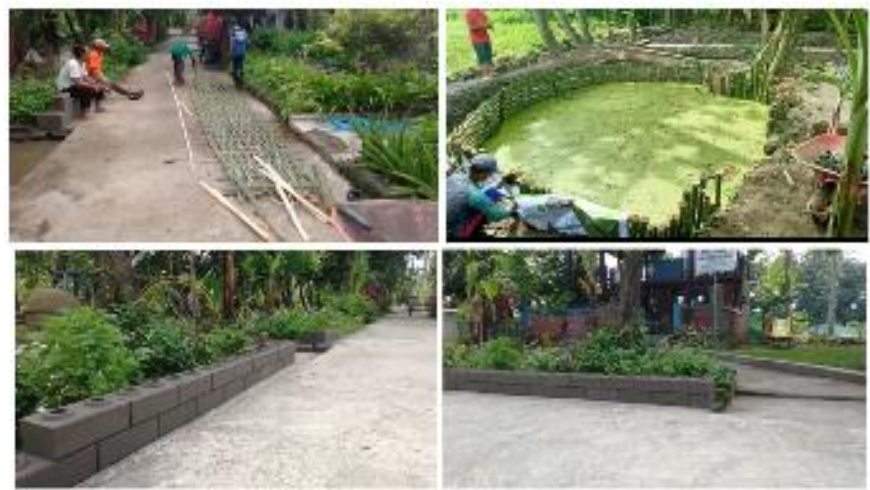

Gambar 19. Proses penataan kolam ikan dan kebun PAUD Edelwys

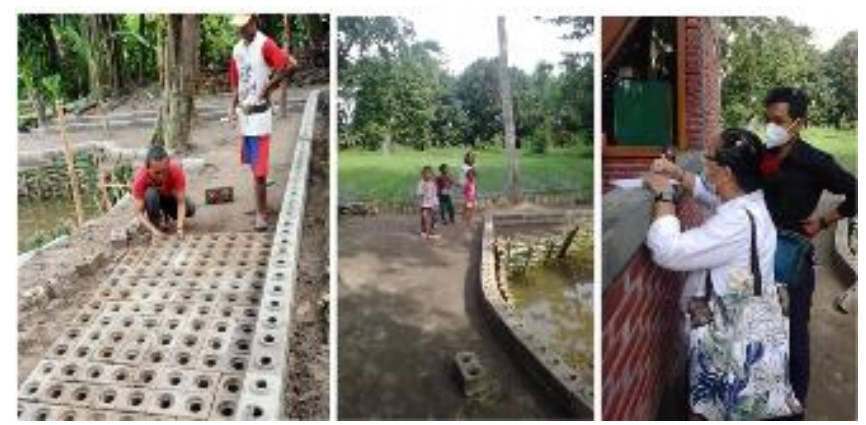

Gambar 20. Penataan taman bermain dan monitoring - evaluasi

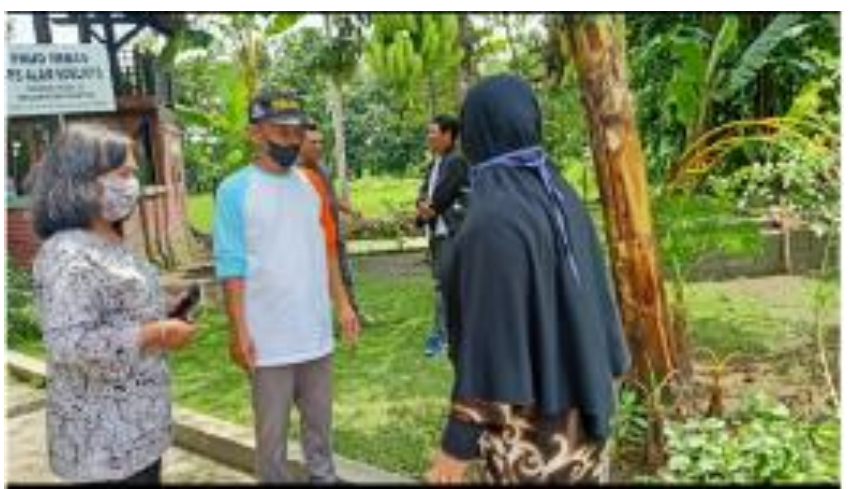

Gambar 21. Dosen prodi Teknologi Pangan, Ekonomi dan Sosial Politik pun ikut terlibat
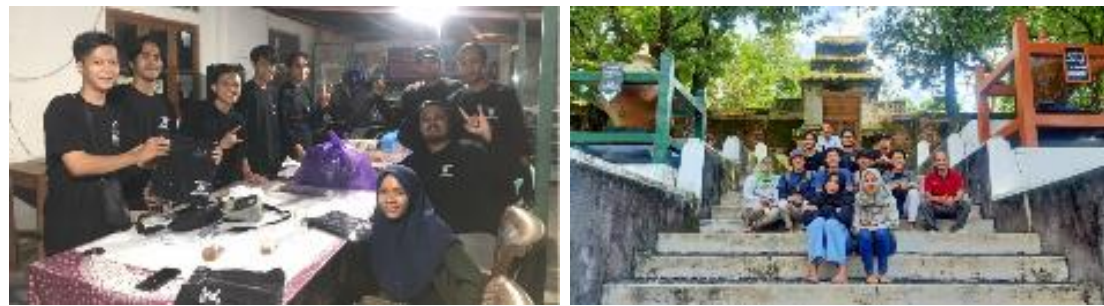

Gambar 22. Hari-hari terakhir kegiatan enggan kembali karena belajar banyak hal dan juga ingin mengenal daerah sekitar dengan refreshing ke Imogiri dan pantai selatan 


\subsection{Kegiatan Serah Terima Pekerjaan dan Aset Kepada Masyarakat}

Serah terima hasil kegiatan dan 2-unit alat pres bata Kobel beserta kelengkapannya yang dihibahkan kepada Dusun dilakukan pada Tanggal 24 Desember 2021 yang dihadiri oleh Bapak Rektor, Prof. DR. Drs. H. Suparno, MSi, didampingi Wakil Rektor 4, Prof. DR. Retno Mawarini Sukmariningsih, SH. MHum., Kepala Bidang Inovasi Dra. Endang. Hal yang mengesankan adalah penjelasan bapak kepala Dusun Serut, Rahmad Tobadiyana, SPd., yang menjelaskan terkait misi dusun menjadi Dusun Serut Hijau dan Pembelajar, maka penataan taman ini sungguh menjadi pusat dan model penampilan dusun yang ramah lingkungan, pusat kehidupan dan pertumbuhan, harapan masa depan. Kepala Desa Palbapang juga hadir dan sangat mengapresiasi kegiatan ini yang diungkapkan dalam sambutannya serta mohon keberlanjutan pendampingan UNTAG Semarang tidak hanya pada Dusun Serut saja, tapi ke dusun lainnya dalam kelurahan Desa Palbapang. Beberapa dokumentasi kegiatan serah terima ditampilkan dalam Gambar 23 berikut.

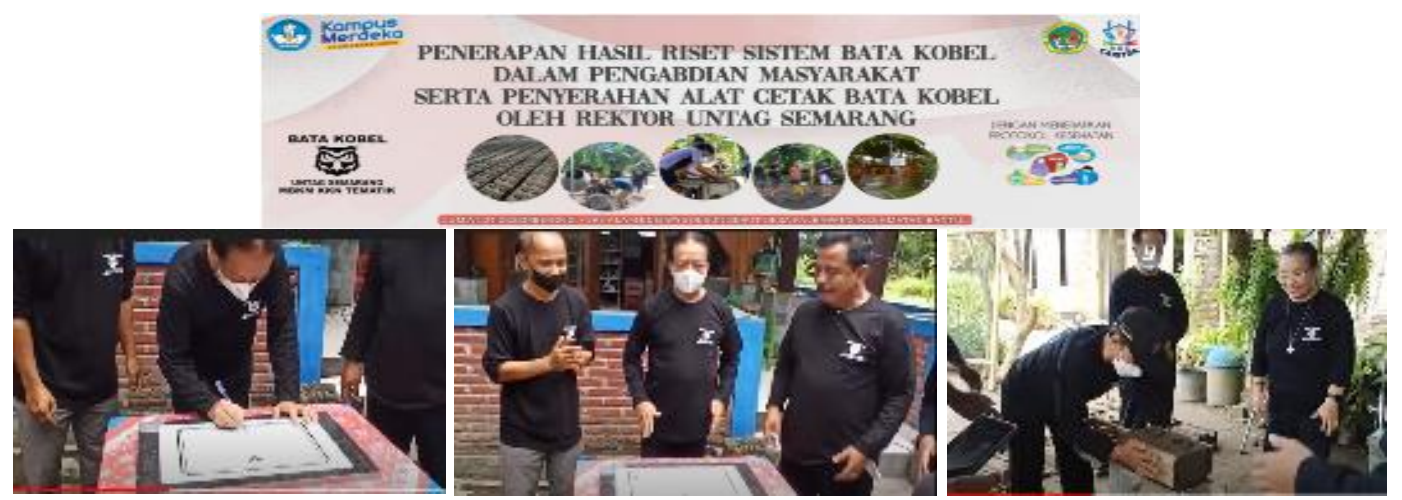

Gambar 23. Foto dokumentasi penyerahan hasil kegiatan dan alat pres Bata Kobel

\section{KESIMPULAN}

Penerapan sistem bata Kobel memberikan kesempatan bagi dosen, mahasiswa, mitra dan masyarakat bersinergi untuk menciptakan suatu taman yang ramah lingkungan, murah dan terjangkau. Kesempatan ini juga menyatukan unsur akademisi, swasta dan masyarakat dalam pengembangan infrastruktur dan kesejahteraan masyarakat.

Bata Kobel ini sudah diterapkan di beberapa daerah di Indonesia, diantaranya rumah tinggal di Nunsui, Kupang-NTT, di Desa Tli'u, TTS-NTT, sanitasi di Desa Rukuramba, Ende, FloresNTT, Gua Maria di Ngalupolo, Ende, Flores-NTT, asrama mahasiswi (17 kamar) di Kupang-NTT, drainase di UNIFLOR, bak distribusi air dalam kerjasama CSR-BNI46 di Tanahmerah, Ende, FloresNTT. Bata Kobel juga telah dimanfaatkan dalam BUMdes Desa Rukuramba. Terbukti Bata Kobel dapat dimanfaatkan untuk berbagai keperluan yaitu membangun rumah, membangun taman, pagar, dan lain sebagainya. Di Dusun Serut, bata Kobel akan dimanfaatkan untuk meningkatkan kualitas fisik lingkungan di Taman Perpustakaan Jayari. HRC Caritra dalam hal ini membantu membuat desain implementasi bata Kobel di Taman Perpustakaan Jayari Dusun Serut.

\section{UCAPAN TERIMA KASIH}

Ucapan terima kasih yang berlimpah kepada Direktorat Jenderal Pendidikan Tinggi, Riset, dan Teknologi yang telah memberi dukungan finansial terhadap pengabdian ini. Ungkapan terima kasih juga kepada masyarakat Dusun Serut yang telah terlibat dan berpartisipasi aktif melaksanakan kegiatan ini, serta HRC Caritra sebagai mitra kerjasama dalam kegiatan ini.

\section{DAFTAR PUSTAKA}

Dirjen Dikti Kemendikbud. (2021). Buku Panduan Indikator Kinerja Utama Perguruan Tinggi Negeri. Dirjen Dikti Kemendikbud. 
Djoko, A. (2013). PEMBELAJARAN KOLABORATIF: Suatu Landasan untuk Membangun Kebersamaan dan Keterampilan. Diklus, Edisi XVII, Nomor 01, September 2013. Hal 292-304.

DRPM-ITS. (2021). Kuliah Kerja Nyata. Diunduh 12 Desember 2021 di alamat website: https://www.its.ac.id/drpm/beranda/program-kegiatan/pengabdian-masyarakat/kkn/

Caritra. (2021). Wawancara pada Masyarakat, Guru PAUD dan Tokoh Masyarakat. Dampak Pengabdian Masyarakat Sistem Bata Kobel di Dusun Serut Palbapang Bantul DIY. 24 Desember 2021

LP3M Universitas Udayana. (2020). Buku Panduan Merdeka Belajar - Kampus Merdeka.

Suparno. (2021). Wawancara pada mahasiswa KKN Tematik. Kesan dan Pengalaman ikut KKN Tematik. 24 Desember 2021.

Suparno. (2021). Peraturan Akademik Universitas 17 Agustus 1945 Semarang

Susilawati, I. W. Tyas, H. M. A. Sutoto. (2021). Batu Pres Tanah Dalam Bangunan Teknik Sipil Pada Masyarakat Pedesaan. Prosiding Simposium Nasional Teknologi Infrastruktur Abad ke-21. Vol 1, Januari 2021. ISBN 978-623-91262-1-6 (no.jil.lengkap EPUB) ISBN 978-623-91262-2-3 (jil.1 EPUB), Hal. 82-88

Susilawati et.al. (2021). Sinergi Perguruan Tinggi Dan CSR-BNI46 Dalam Pembangunan Sarana Distribusi Air Bersih Sistem Batu-Pres-Tanah Bertautan Yang Melibatkan Masyarakat. Nemui Nyimah: Jurnal Pengabdian kepada Masyarakat. Vol 1, No. 1, 2021, hlm.1-12

Susilawati, Sungsang ANP, Indah Wahyuning Tyas. (2019). Kolam Tampung Penerapan Inovasi Teknologi Batu Pres Tanah Murah Biaya Konstruksi, Operasi dan Pemeliharaan. Prosiding KoNTekS 13, "Inovasi Sains dan Teknologi dalam Penerapan Infrastruktur Berbasis Mitigasi Bencana dan Berwawasan Lingkungan". ISBN: 978-979-98659-6-0. Vol 1, Struktur, Material, Manajemen Rekayasa Konstruksi, Banda Aceh, 19-21 September 2019. p.230-238.

Susilawati and Tyas, I.W. (2018). Lock-brick System for Sustainable and Environment Infrastructure Building Materials. IOP Conference Series: Materials Science and Engineering 2018 International Conference on Building Materials and Construction (ICBMC 2018), p.233240. ISSN: 17578981 E-ISSN: 1757899X Vol 371 Nha Trang, Vietnam, February 23-25, 2018. Editor: Prof. Low Sui Pheng, National University of Singapore

Susilawati and Indah, W.T. (2017). Lock-brick System for Environmentally Friendly Building Infrastructure. Proceeding Book "Sustainable Infrastructure and Built Environment, Past, Present and Future" SIBE 2017, p.82-93. ISBN: 978-979-98278-6-9, Faculty of Civil and Environmental Engineering, Bandung, September, 26th-27th, 2017

Susilawati, Veronika dan Shuayib. (2017). Sistem Lock-Brick Mendukung Pembangunan Infrastruktur Biaya Rendah dan Berkelanjutan. Prosiding KoNTekS 11, "Meningkatkan Daya Saing Industri Konstruksi Dalam Persaingan di Tingkat Global Menuju Pembangunan Infrastruktur Berkelanjutan. Paper ID: Air 19-26. ISBN 978-602-60662-2-0, Jakarta, 26-27 Oktober 2017

Vania Zulfa, Milson Max, Iskar Hukum dan Irfan Ilyas. (2017). ISU-ISU KRITIS LINGKUNGAN DAN PERSPEKTIF GLOBAL JGG- Jurnal Green Growth dan Manajemen Lingkungan Vol.5 No.1 Juli 2016. p-ISSN: 2303-2332; e-ISSN: 2597-8020. DOI : doi.org/10.21009/jgg.051.03 